\title{
SCIDoC
}

Infer, Interpret \& Inspire Science

\author{
International Journal of Dentistry and Oral Science (IJDOS) \\ ISSN: 2377-8075
}

\section{Prevalence and Associated Factors for Dental Arch Crowding In Mixed Dentition Cases Reporting To Private Dental College}

Research Article

\section{Vaishali. $\mathrm{S}^{1}$, Ravindra Kumar Jain ${ }^{2 *}$, Revathi Duraisamy ${ }^{3}$}

${ }^{1}$ Saveetha Dental College and Hospitals, Saveetha Institute of Medical and Technical Sciences, Saveetha University, Chennai, India.

${ }^{2}$ Reader, Department of Orthodontics, Saveetha Dental College and Hospitals, Saveetha Institute of Medical and Technical Sciences, Saveetha University, Chennai, 600077, India.

${ }^{3}$ Senior Lecturer, Department of Prosthodontics, Saveetha Dental College and Hospitals, Saveetha Institute of Medical and Technical Sciences, Saveetha University, Chennai, 600077, India.

\section{Abstract}

\begin{abstract}
The mixed dentition is an important developmental state, to the undisturbed occlusal relationship. The eruption of the first permanent molar plays a critical role in maintaining the inter arch space and sagittal occlusal relationship. Dental crowding occurs when there is discrepancy between required space and space present between arch, \& most commonly see. In the anterior teeth. Crowding represents one of the most frequent complaints of patients seeking orthodontists. The aim of the study is to assess the prevalence of crowding in mixed dentition cases reporting to private dental college. It is a university setting study, conducted in a private dental college. 1082 children in their mixed dentition stage of tooth development were randomly selected. Data regarding crowding was obtained after reviewing case sheets of patients in the age group 6-12 years. The data was entered in excel and imported to SPSS and variables were defined. The data included presence of crowding, dental malocclusion present and the arch involved. Descriptive statistics was used to describe the age and gender distribution of the study population. Chi square test was used to associate crowding with age, gender, dental malocclusion .Out of 1082 children in the age group between 6-12 years, crowding was present in 70 children $(6.47 \%)$. Most common arch involved in crowding was the mandibular arch $(56 \%)$. Positive correlation was found between age and crowding. 10-12 years old children had maximum crowding $(3.14 \%)(\mathrm{p}<0$. 001). Positive correlation was found between gender and crowding $(\mathrm{p}<0.05)$. Males had maximum crowding $(4.62 \%)$ when compared to females $(1.85 \%)$. No association was found between dental malocclusion and crowding. Within the limits of the study, crowding was prevalent in $6.47 \%$ of the children in the mixed dentition stage. 10-12 years old children had maximum crowding which was statistically significant. Also, males had maximum crowding than females which was statistically significant.
\end{abstract}

Keywords: Age; Crowding; Gender; Malocclusion; Mandible; Maxilla; Mixed Dentition.

\section{Introduction}

Growing demands of the global population has unleashed the new era of a better standard living which is rising exponentially. The people of the world are concerned about the oro-facial region mostly because it draws the most attention from the other people in interpersonal interactions and it dictates the vocal, physical and emotional communication [1]. Within that, the tooth component which is also concerned with appearance plays an important role in overall ethical value, psychological impact, and social consequences [2].
Malocclusion can be defined as an occlusion in which there is a mal-relationship between the arches in any of the planes or in which there are anomalies in tooth position, number,form and developmental position of teeth beyond normal limits [3]. Clinically, it can be manifested in a broad range of variations from a signified rotation of a tooth, a small diastema to more severe forms of crowding, spacing, superior protrusion and in a combination of several traits [4]. Malocclusion is one of the most common oral disorders among children, and it affects not only the oral masticatory function but also the craniofacial development and facial appearance [5]. Children with certain malocclusion traits appear to have more problems related to psychology and social

\section{*Corresponding Author}

Ravindra Kumar Jain,

Reader, Department of Orthodontics, Saveetha Dental College and Hospitals, Saveetha Institute of Medical and Technical Sciences, Saveetha University, Chennai, 600077, India. Tel: 9884729660

E-mail: ravindrakumar@saveetha.com

Received: November 10, 2020

Accepted: December 15, 2020

Published: December 18,2020

Citation: Vaishali. S, Ravindra Kumar Jain, Revathi Duraisamy. Prevalence and Associated Factors for Dental Arch Crowding In Mixed Dentition Cases Reporting To Private Dental College. Int J Dentistry Oral Sci. 2020;7(12):1256-1260. doi: http://dx.doi.org/10.19070/2377-8075-20000248

Copyright: Ravindra Kumar Jain 2020 . This is an open-access article distributed under the terms of the Creative Commons Attribution License, which permits unrestricted use, distribution and reproduction in any medium, provided the original author and source are credited. 
interactions and even their quality of life suffers when they reach adulthood [6]. For this reason, malocclusion is regarded as an emerging health issue.

Malocclusion can occur due to a variety of causes. Broadly speaking malocclusion is caused by either genetic or environmental factors [7]. Hereditary has for long been attributed for genetically as one of the causes of malocclusion. Another region attributed for genetically determined malocclusion is the racial, ethnic and regional inter-mixture, which might have led to the uncoordinated inheritance of teeth and jaws [8]. Environmental factors like prenatal influences from maternal diet, metabolism, drug induced, possible injury or trauma, infections and birth injuries also play an important role in determining the fate of tooth alignment [9]. Predisposing factors like dietary problems, abnormal habits, posture, accidents and trauma also led to an abnormality in teeth arrangement or malocclusion [10].

The mixed dentition is an important developmental state, to the undisturbed occlusal relationship. The eruption of the first permanent molar plays a critical role in maintaining the inter arch space and sagittal occlusal relationship [11]. Several longitudinal observations have revealed that a substantial number of malocclusions occurred during this period and the accumulated evidence has indicated that early intervention starting from the mixed dentition would benefit the youngsters with crowding [12].

Dental crowding, also referred as swarming, can be characterised as an inconsistency between tooth size and arch dimension which results in malocclusion [13]. Crowding can be classified as primary, secondary, or tertiary, when it affects the mixed dentition in the first transitional period, second transitional period \& permanent dentition respectively [14]. Dental crowding occurs when there is discrepancy between required space and space present between arch, \& most commonly seen in the anterior teeth. When there is shortage of space for the arrangement of teeth in the dental arch, teeth experience the ill effects of rotation, dislocated eruption etc [15] The factors that may contribute to teeth crowding are broad teeth, bony bases and also the developmental pattern towards a decreased facial skeletal size without a relating diminish in tooth size . Crowded teeth are very difficult to clean properly and thoroughly, which results in poor mouth cleanliness and further dental and medical problems. Crowding represents one of the most frequent complaints of patients seeking orthodontists.

Previously our team had conducted numerous clinical trials [1624] and in vitro studies [25, 26], and systematic reviews [27-30] over the past 5 years. Now we are focussing on epidemiological surveys. The idea for this survey stemmed from the current interest in the community.

So this study was designed to assess the prevalence of dental arch crowding in mixed dentition subjects. Early intervention minimises occlusal adverse effects resulting in better prognosis.

\section{Materials and Methods}

\section{Study setting}

It is a university setting study, conducted from the available case records of subjects reporting to Saveetha Dental College and
Hospitals. The pros of the study is easy retrieval of data. The cons of the study are that it is limited to a certain population, researcher's personal bias. Study population included children in the age group between 6-12 years with mixed dentition selected randomly from those who reported to Saveetha Dental College. The study was initiated after approval from the institutional review board and it was covered by the following ethical approval number; SDC/SIHEC/2020/DIASDATA/0619-0320.

\section{Sampling}

It is a retrospective study. Data was collected from July 1, 2019 to March 31st 2020. Cross verification of data for errors was done by photographic evaluation.

\section{Data collection}

Out of 86000 subjects who reported from July, 2019 to March 2020,1082 case records of 6-12 year old subjects were included in the study. Patients details -name, age, gender, presence of crowding, arch involved, dental malocclusion were retrieved after analysing these case records. Data was entered in a methodical manner and imported to SPSS and variables were defined. Incomplete or censored data was excluded from the study.

\section{Analytics}

The collected data was validated, tabulated and analysed with Statistical Package for Social Sciences for Windows, version 23.0 (SPSS Inc., Chicago, IL, USA) and results were obtained. Independent variables included age, gender. Dependent variables included crowding, dental malocclusion. Descriptive analysis was used to describe age and gender distribution of the study population. Chi square test was used to associate crowding with age, gender and dental malocclusion.

\section{Results and Discussion}

Malocclusion has been shown to affect oral health, increased prevalence of dental caries and can cause Temporomandibular joint disorders. The prevalence of malocclusion varies from country to country and among different age and sex group.

In relation to prevalence of crowding, it is seen that out of 1082 children, crowding was present in 70 children $(6.47 \%)$ and was absent in 1012 children $(93.53 \%$ ) [Figure 1]. In relation to association between age and crowding it was seen that positive correlation was found between age and crowding. Crowding was more prevalent as age increases. 10 to 12 years age group had maximum crowding (3.14\%). These results were statistically significant (Pearson Chi square $=23.127, \mathrm{p}=0.000)$ [Figure 2]. In relation to the association between gender and crowding, it was seen that positive correlation was found between gender and crowding. Crowding was more prevalent in males $(4.62 \%)$ when compared to females $(1.85 \%)$. These results were statistically significant (Pearson Chi square $=3.957, \mathrm{p}=0.047$ ) [Figure 3]. In relation to association between dental malocclusion and crowding, it was seen that crowding was more prevalent in class I occlusion $(5.91 \%)$. But these were not statistically significant (Pearson Chi square= $0.369, \mathrm{p}=0.544)$ So there is no association between dental malocclusion and crowding [Figure 4]. 
Figure 1. Simple bar chart shows prevalence of crowding in the study population. $\mathbf{X}$ axis denotes prevalence of crowding and $\mathrm{Y}$ axis denotes the percentage of participants in each group. Out of 1082 children, crowding was present in 70 children $(6.47 \%)$ and was absent in 1012 children $(93.53 \%)$.

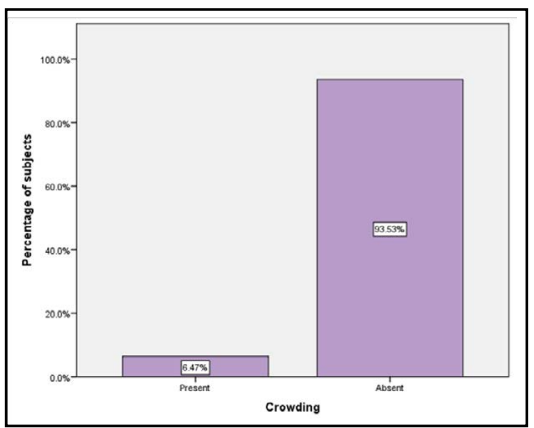

Figure 2. Bar chart shows association between age and crowding. $\mathrm{X}$ axis denotes the different age groups and $\mathrm{Y}$ axis denotes the percentage of crowding in each age group. Crowding was more prevalent as age increases. Chi square association was done and found to be significant(Pearson Chi square $=23.127, \mathrm{p}=0.000(<0.05)$ ) proving crowding (blue) was more common in the 10-12 years age group.

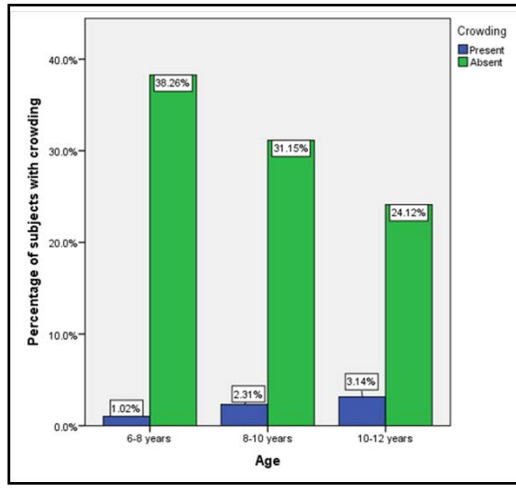

Figure 3. Bar chart shows association between gender and crowding. $\mathrm{X}$ axis denotes the different gender and $\mathrm{Y}$ axis denotes the percentage of crowding in each gender. Chi square association was done and found to be significant (Pearson Chi square $=3.957, \mathrm{p}=0.047(<0.05))$, proving crowding $($ Blue $)$ was more prevalent in males when compared to females.

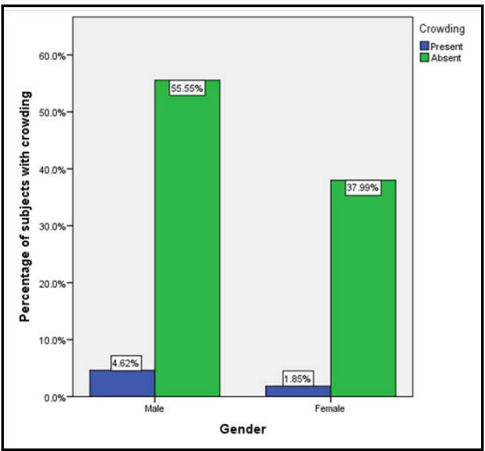

Figure 4. Bar chart shows association between dental malocclusion and crowding. $X$ axis denotes the different types of malocclusion and $\mathrm{Y}$ axis denotes the percentage of crowding in each type of dental malocclusion. Chi-square test was done and was found to be statistically not significant (Pearson Chi square $=0.369, \mathrm{p}=0.544(>0.05)$ ). Crowding (blue) was more prevalent in class I occlusion.

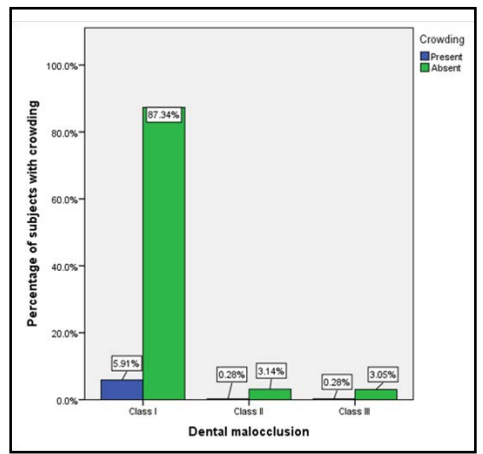


In relation to the prevalence of crowding, it was found that it was prevalent in $6.5 \%$ of the study population. Literature by Massler et al [31] stated that crowding was present in $21.5 \%$ of the children in the mixed dentition stage. The probable reasons would be differing sample size and geographic location.

In relation to the association between age and crowding, crowding was more prevalent in 10-12 years, as age increases crowding increases, which was similar to the study by Shivakumar et al [32]. The reason for crowding as age increases, it becomes prevalent is due to the eruption of permanent teeth. However, literature by Gelgor et al [6] stated that crowding was maximum in the 7 to 8 years age group which was contradictory to the present study. The reasons could be differing sampling size, geographic location $\&$ examiner's subjectivity.

In relation to the association between gender and crowding, contradictory findings were found in literature by Xin Yu et al [33], where crowding was more prevalent in females when compared to males. The possible reasons for these variations may be due to differing sample size and geographic location.

In relation to the association between dental malocclusion and crowding, contradictory findings were found in literature by Ansai et al [34] and Hassan et al [35], where crowding was maximum in class I occlusion which was statistically significant. However, present study didn't show any correlation between dental malocclusion and crowding. The probable reason for this variation could be sample size was large when compared to the present study.

The limitations of the study includes sample size, single centered study and examiner's subjectivity.

The future scope of this study is to do extensive research with a large sample size to know about prevalence of crowding \& its associated risk factor factors which might help in early intervention resulting in better prognosis.

\section{Conclusion}

Within the limits of the study, the prevalence of crowding among subjects in mixed dentition stage was $6.5 \%$. Crowding was more common in 10-12 yr old male children than in females of the same age group. Crowding was not associated with any particular type of malocclusion.

\section{Acknowledgements}

We take pleasure to express our sincere gratitude to the University for granting us permission to utilize the data from patient records for the study.

\section{Author's Contribution}

First author Vaishali.S performed data collection, analysis and interpretation and wrote the manuscript.

Second author Ravindra Kumar Jain contributed to conception, study design, analysis, interpretation and critically revised the manuscript.
Third author Revathi Duraisamy contributed to review the manuscript.

All the authors have discussed the results and contributed to the final manuscript.

\section{References}

[1]. Shetty R, Hegde V, Shetty PJ. Assessment of malocclusion status, dentition status, and treatment needs among 15-year-old school children of Mangalore. Indian J Dent Res. 2018 Jan-Feb;29(1):109-116. PMID: 29442095.

[2]. Kumar P, Londhe SM, Kotwal A, Mitra R. Prevalence of malocclusion and orthodontic treatment need in schoolchildren - An epidemiological study. Med J Armed Forces India. 2013 Oct;69(4):369-74. PMID: 24600146.

[3]. Jha K, Saha S, Gv J, Narang R, Biswas G, Sood P, Garg A, Narayan M. Prevalence of Malocclusion and its Psycho-Social Impact among 12 To 15-Year-old School Children in Lucknow City. J Clin Diagn Res. 2014 Oct;8(10):ZC36-9. PMID: 25478444.

[4]. Graber TM. Orthodontic diagnosis and treatment planning. American Journal of Orthodontics. 1984; 97.

[5]. Martins-Júnior PA, Marques LS, Ramos-Jorge ML. Malocclusion: social, functional and emotional influence on children. J Clin Pediatr Dent. 2012 Fall; 37(1): 103-8. PMID: 23342575.

[6]. Gelgör IE, Karaman AI, Ercan E. Prevalence of malocclusion among adolescents in central anatolia. Eur J Dent. 2007 Jul;1(3):125-31. PMID: 19212555.

[7]. Dimberg L, Lennartsson B, Arnrup K, Bondemark L. Prevalence and change of malocclusions from primary to early permanent dentition: a longitudinal study. Angle Orthod. 2015 Sep;85(5):728-34. PMID: 25867255.

[8]. Bhalajhi SI. Orthodontics. Arya (Medi) Publishing House. 2003; 534.

[9]. Graber TM. RL Vanarsdall, Orthodontics: Current Principles and Techniques. Year Book Medical Pub. 2000.

[10]. Góis EG, Vale MP, Paiva SM, Abreu MH, Serra-Negra JM, Pordeus IA. Incidence of malocclusion between primary and mixed dentitions among Brazilian children. A 5-year longitudinal study. Angle Orthod. 2012 May;82(3):495-500. PMID: 21981755.

[11]. Gianelly AA. Treatment of crowding in the mixed dentition. Am J Orthod Dentofacial Orthop. 2002 Jun;121(6):569-71. PMID: 12080302.

[12]. Borzabadi-Farahani A. An insight into four orthodontic treatment need indices. Prog Orthod. 2011 Nov;12(2):132-42. PMID: 22074838.

[13]. Littlewood SJ, Mitchell L. An introduction to orthodontics. Oxford university press; 2019 Mar 16.

[14]. Radnzic D. Dental crowding and its relationship to mesiodistal crown diameters and arch dimensions. Am J Orthod Dentofacial Orthop. 1988 Jul;94(1):50-6. PMID: 3164582.

[15]. Howe RP, McNamara JA Jr, O'Connor KA. An examination of dental crowding and its relationship to tooth size and arch dimension. Am J Orthod. 1983 May;83(5):363-73. PMID: 6573844.

[16]. Sivamurthy G, Sundari S. Stress distribution patterns at mini-implant site during retraction and intrusion--a three-dimensional finite element study. Prog Orthod. 2016;17:4. PMID: 26780464.

[17]. Samantha C, Sundari S, Chandrasekhar S, Sivamurty G, Dinesh S. Comparative Evaluation of Two Bis-GMA Based Orthodontic Bonding Adhesives - A Randomized Clinical Trial. J Clin Diagn Res. 2017 Apr;11(4):ZC40ZC44. PMID: 28571259.

[18]. Felicita AS. Quantification of intrusive/retraction force and moment generated during en-masse retraction of maxillary anterior teeth using mini-implants: A conceptual approach. Dental Press J Orthod. 2017 SepOct;22(5):47-55. PMID: 29160344.

[19]. Rubika J, Felicita AS, Sivambiga V. Gonial angle as an indicator for the prediction of growth pattern. World J Dent. 2015;6(3):161-3.

[20]. Jain RK, Kumar SP, Manjula WS. Comparison of intrusion effects on maxillary incisors among mini implant anchorage, j-hook headgear and utility arch. J Clin Diagn Res. 2014 Jul;8(7):ZC21-4. PMID: 25177631.

[21]. Pandian KS, Krishnan S, Kumar SA. Angular photogrammetric analysis of the soft-tissue facial profile of Indian adults. Indian J Dent Res. 2018 MarApr;29(2):137-143. PMID: 29652003.

[22]. Felicita AS, Chandrasekar S, Shanthasundari KK. Determination of craniofacial relation among the subethnic Indian population: a modified approach - (Sagittal relation). Indian J Dent Res. 2012 May-Jun;23(3):305-12. PMID: 23059564.

[23]. Dinesh SP, Arun AV, Sundari KK, Samantha C, Ambika K. An indigenously designed apparatus for measuring orthodontic force. J Clin Diagn Res. 2013 
Nov;7(11):2623-6. PMID: 24392423.

[24]. Felicita AS. Orthodontic extrusion of Ellis Class VIII fracture of maxillary lateral incisor - The sling shot method. Saudi Dent J. 2018 Jul; 30(3): 265269. PMID: 29942113.

[25]. Kamisetty SK, Verma JK, Arun, Sundari S, Chandrasekhar S, Kumar A. SBS vs Inhouse Recycling Methods-An Invitro Evaluation. J Clin Diagn Res. 2015 Sep;9(9):ZC04-8. PMID: 26501002.

[26]. Ramesh Kumar KR, Shanta Sundari KK, Venkatesan A, Chandrasekar S. Depth of resin penetration into enamel with 3 types of enamel conditioning methods: a confocal microscopic study. Am J Orthod Dentofacial Orthop. 2011 Oct;140(4):479-85. PMID: 21967934.

[27]. Krishnan S, Pandian S, Kumar S A. Effect of bisphosphonates on orthodontic tooth movement-an update. J Clin Diagn Res. 2015 Apr;9(4):ZE01-5. PMID: 26023659.

[28]. Vikram NR, Prabhakar R, Kumar SA, Karthikeyan MK, Saravanan R. Ball Headed Mini Implant. J Clin Diagn Res. 2017 Jan;11(1):ZL02-ZL03. PMID: 28274084.

[29]. Viswanath A, Ramamurthy J, Dinesh SP, Srinivas A. Obstructive sleep apnea: awakening the hidden truth. Niger J Clin Pract. 2015 Jan-Feb;18(1):1-7. PMID: 25511335.

[30]. Felicita AS. Orthodontic management of a dilacerated central incisor and partially impacted canine with unilateral extraction - A case report. Saudi
Dent J. 2017 Oct;29(4):185-193. PMID: 29033530.

[31]. MASSLER M, FRANKEL JM. Prevalence of malocclusion in children aged 14 to 18 years. Am J Orthod. 1951 Oct;37(10):751-68. PMID: 14877987.

[32]. Shivakumar KM, Chandu GN, Subba Reddy VV, Shafiulla MD. Prevalence of malocclusion and orthodontic treatment needs among middle and high school children of Davangere city, India by using Dental Aesthetic Index. J Indian Soc Pedod Prev Dent. 2009 Oct-Dec;27(4):211-8. PMID: 19915271.

[33]. Shivakumar KM, Chandu GN, Subba Reddy VV, Shafiulla MD. Prevalence of malocclusion and orthodontic treatment needs among middle and high school children of Davangere city, India by using Dental Aesthetic Index. J Indian Soc Pedod Prev Dent. 2009 Oct-Dec;27(4):211-8. PMID: 19915271.

[34]. Ansai T, Miyazaki H, Katoh Y, Yamashita Y, Takehara T, Jenny J, et al. Prevalence of malocclusion in high school students in Japan according to the Dental Aesthetic Index. Community Dent Oral Epidemiol. 1993 Oct; 21(5): 303-5. PMID: 8222606.

[35]. Alogaibi YA, Murshid ZA, Alsulimani FF, Linjawi AI, Almotairi M, Alghamdi $\mathrm{M}$, et al. Prevalence of malocclusion and orthodontic treatment needs among young adults in Jeddah city. J Orthod Sci. 2020 Feb 12;9:3. PMID: 32166082 . 